\title{
UM DIÁLOGO COM O ALUNO NA AVALIAÇÃO DA EDUCAÇÃO A DISTÂNCIA: AS MELHORES PRÁTICAS EM METODOLOGIAS ATIVAS COM O USO DAS TDICS NO MOODLE
}

\author{
Daniele Cristine Novaes Sucena de Almeida \\ Especialista em Planejamento, Implementação e Gestão da EAD e Administração em Banco de Dados. \\ Chefe da Seção de Ensino a Distância da EsEFEx. \\ https://orcid.org/0000-0003-1181-1952 \\ Sabrina Sousa \\ Coordenadora Pedagógica / Especialista em Gestão de Processos Educativos e Especialista em \\ Supervisão Pedagógica de Educação Profissional. \\ https://orcid.org/0000-0002-5014-3443 \\ Regina Célia Pereira de Moraes \\ Pós-Doutora em Serviço Social PUC-RJ. Pós-Doutora em Ciência da Informação- IBICT. Doutora em \\ Engenharia de Sistemas, PESC/COPPE/UFRJ. Bacharel em Direito (UERJ) \\ https://orcid.org/0000-0001-6590-9707 \\ Alessandro Jatobá \\ Analista de Gestão em Saúde no Centro de Estudos Estratégicos da FIOCRUZ. Professor no Centro \\ Universitário Carioca. Doutor em Engenharia de Produção COPPE/UFRJ \\ https://orcid.org/0000-0002-7059-6546 \\ Leonardo Monteiro Trotta \\ SEEDUC - Secretaria Estadual de Educação \\ https://orcid.org/0000-0001-7411-9352
}

Data de submissão: 02/05/2021

Data de aprovação: 16/06/2021

\section{RESUMO}

O objetivo é transmitir novas formas de ensinar e aprender e para tanto, é preciso propor continuamente uma reflexão sobre o processo educacional na modalidade a distância, ter um diálogo com o aluno, entender como ele quer aprender e introduzir metodologias ativas com o uso de Tecnologias Digitais Informação e Comunicação (TDICs) no Ambiente Virtual de Aprendizagem (AVA) chamado Moodle. A experiência que se traz neste trabalho foi adotada nos cursos de ensino superior de uma organização de ensino pública federal ofertados na Educação a Distância (EaD). Em nível mais específico objetiva-se apresentar as ferramentas tecnológicas disponíveis que podem ser trabalhadas pelos professores no Moodle. Os métodos utilizados foram essenciais para o desenvolvimento desse trabalho, sendo realizadas pesquisas após a implementação das ferramentas tecnológicas. Os resultados da pesquisa revelaram que as implementações das TDICs no Moodle foram satisfatórias e os participantes desejam encontrar mais tecnologias digitais similares na plataforma, em que o aluno foi o protagonista em todas as atividades propostas. A introdução de metodologias ativas e de tecnologias dialógicas na avaliação do processo educativo também gerou uma grande repercussão positiva impulsionando os professores e tutores a planejar e executar tarefas diferenciadas. Por fim, concluiu-se, que é possível 
aplicar metodologias ativas na educação a distância com o uso de TDICs para uma aprendizagem significativa, sendo o docente como mediador e o aluno protagonista a fim de alcançar as melhores práticas pedagógicas de ensino conforme o plano de aula do professor.

Palavras-chave: educação a distância (EaD); ambiente virtual de aprendizagem (AVA); moodle; tecnologias digitais da informação e comunicação (TDICs); metodologias ativas; avaliação

\section{A DIALOGUE WITH THE STUDENT IN THE EVALUATION OF DISTANCE EDUCATION: BEST PRACTICES IN ACTIVE METHODOLOGIES WITH THE USE OF TDICS IN MOODLE}

\section{ABSTRACT}

The objective is to transmit new ways of teaching and learning and, therefore, it is necessary to continually propose a reflection on the educational process in the distance modality, have a dialogue with the student, understand how he wants to learn and introduce active methodologies with the use of Technologies Digital Information and Communication (TDICs) in the Virtual Learning Environment (AVA) called Moodle. The experience that this work brings was adopted in higher education courses of a federal public education organization offered in Distance Education (EAD). At a more specific level, the objective is to present the technological tools available that can be used by teachers in Moodle. The methods used were essential for the development of this work, research being carried out after the implementation of the technological tools. The survey results revealed that the implementations of TDICs in Moodle were satisfactory and participants want to find more similar digital technologies on the platform, where the student was the protagonist in all proposed activities. The introduction of active methodologies and dialogic technologies in the evaluation of the educational process also generated a great positive impact, encouraging teachers and tutors to plan and execute differentiated tasks. Finally, it was concluded that it is possible to apply active methodologies in distance education with the use of TDICs for meaningful learning, with the teacher as a mediator and the student as protagonist in order to achieve the best pedagogical teaching practices according to the plan of teacher's class.

Keywords: distance education (EAD); virtual learning environment (VLE); moodle; digital information and communication technologies (TDICs); active methodologies; evaluation

\section{UN DIÁLOGO CON EL ESTUDIANTE EN LA EVALUACIÓN DE LA EDUCACIÓN A DISTANCIA: BUENAS PRÁCTICAS EN METODOLOGÍAS ACTIVAS CON EL USO DE TDICS EN MOODLE}

\section{RESUMEN}

El objetivo es transmitir nuevas formas de enseñar y aprender $y$, por ello, es necesario proponer continuamente una reflexión sobre el proceso educativo en la modalidad a 
distancia, dialogar con el alumno, entender cómo quiere aprender e introducir metodologías activas con el uso de Tecnologías de Información y Comunicación Digital (TDICs) en el Ambiente Virtual de Aprendizaje (AVA) denominado Moodle. La experiencia que aporta este trabajo fue adoptada en cursos de educación superior de una organización federal de educación pública que se ofrece en Educación a Distancia (EAD). A un nivel más específico, el objetivo es presentar las herramientas tecnológicas disponibles que pueden ser utilizadas por los profesores en Moodle. Los métodos utilizados fueron fundamentales para el desarrollo de este trabajo, realizándose investigaciones posteriores a la implementación de las herramientas tecnológicas. Los resultados de la encuesta revelaron que las implementaciones de TDICs en Moodle fueron satisfactorias y los participantes quieren encontrar tecnologías digitales más similares en la plataforma, donde el alumno sea el protagonista en todas las actividades propuestas. La introducción de metodologías activas y tecnologías dialógicas en la evaluación del proceso educativo también generó un gran impacto positivo, incentivando a profesores $y$ tutores a planificar $y$ ejecutar tareas diferenciadas. Finalmente, se concluyó que es posible aplicar metodologías activas en la educación a distancia con el uso de TDICs para el aprendizaje significativo, con el docente como mediador y el alumno como protagonista para lograr las mejores prácticas pedagógicas de enseñanza según el plan de clase del maestro.

Palabras Clave: educación a distancia (EAD); ambiente virtual de aprendizaje (AVA); moodle; tecnologías de la información y la comunicación digitales (TDIC); metodologías activas; evaluación;

\section{INTRODUÇÃO}

As Tecnologias Digitais da Informação e Comunicação (TDICs) são instrumentos utilizados como mediação da aprendizagem, capazes de melhorar a comunicação e o relacionamento entre aluno e professor na transmissão de conteúdos educacionais.

Implementar tecnologias para o setor educacional com o uso das metodologias ativas significa planejar uma ação em que o aluno assume a função de protagonista e 0 professor como mediador do processo.

Pensando nas estratégias adotadas e culturas vivenciadas na modalidade presencial, muitos profissionais da área de educação perceberam a necessidade de utilizar as TDICs e metodologias ativas também na educação a distância com objetivo de melhorar a qualidade do ensino, visto que a EaD anteriormente era utilizada como um espaço virtual para repositório de arquivos digitais.

A educação a distância está sendo o foco principal de muitos estudos, devido ao desenvolvimento econômico nos últimos anos e rentabilidade financeira, mas ainda é preciso romper alguns paradigmas e implementar novas estratégias pedagógicas e tecnológicas.

Atualmente, o Moodle é um Ambiente Virtual de Aprendizagem (AVA) mais utilizado em todo mundo e possui diversas ferramentas digitais capazes de fazer integração com outras tecnologias utilizadas na modalidade presencial para melhorar a qualidade do ensino.

Sendo assim, o presente trabalho objetiva-se apresentar experiências no uso de tecnologias digitais da comunicação e da informação (TDICs), com metodologias ativas aplicadas na educação a distância e como novas estratégias pedagógicas em um curso 
EaD. Ao final do módulo foi utilizado um método com aplicação de um questionário para saber a opinião dos alunos através da ferramenta própria do Moodle chamada "Pesquisa".

\section{REFERENCIAL TEÓRICO}

\subsection{A reorganização da prática educacional e metodologias ativas}

Para Manfredinho a "era digital é a possibilidade de superar a fragilidade da instituição escola por meio da revitalização do professor, que tem uma missão especial de complementar a formação do aluno para o mundo adulto, pensante, livre, ético e criativo". (2001, p.41). Tais mudanças no ensino tradicional eram necessárias, a fim de operacionalizar o avanço da modernidade, em que essa prática exige que o aluno seja estimulado a desenvolver a reflexão, autonomia e o pensamento crítico.

É evidente na área educacional o uso das Tecnologias da Informação e Comunicação (TIC) como meio de auxílio e aperfeiçoamento do cotidiano escolar como um tema recorrente, seja voltando-se para a formação docente, ensino-aprendizagem, gestão escolar ou avaliação do saber construído pelos alunos em sala de aula. $O$ ensino remoto em caráter emergencial consoante com o quadro social vigente, torna o tema ainda mais relevante para a comunidade acadêmica, bem como para os diversos profissionais do segmento educacional, trazendo novos elementos para a discussão em torno do ensino híbrido e suas possibilidades para a modernização das escolas. (ANJOS et al., 2020)

De acordo com Cambi (1999) esse movimento provocou remodelação no conceito de ensino, ao refletir acerca da importância e do respeito à individualidade de cada aluno no processo de ensino e aprendizagem. Diante desse cenário, diversas metodologias começaram a ser difundidas nas escolas como alternativa para um ensino que visa 0 protagonismo do aluno.

As metodologias caracterizam a relação entre estudantes e professores, refletindo as finalidades educacionais, o projeto político pedagógico e o currículo, em que referenciam as técnicas de ensino e o uso das tecnologias, contribuindo também para a construção do eu, valores e perspectivas pessoais ao longo do processo educativo. As metodologias ativas visam oportunizar a aprendizagem dos estudantes e fundamentar 0 ato de ensinar, trazendo os alunos para o centro da ação pedagógica e o professor como o mediador da aprendizagem.

Para Horn e Staker (2015) com a utilização de tecnologia aliada ao processo pedagógico, é possível criar métodos de ensino capazes de atender os diferentes ritmos e estilos de aprendizagem do estudante. Nesse sentido, o uso das metodologias ativas com as tecnologias digitais da comunicação e da informação (TDICs) favorecem uma aprendizagem ativa, desafiadora, inovadora e o desenvolvimento do pensamento crítico.

\subsection{Tecnologias digitais da informação e da comunicação (TDICs)}

Thaís Cristina Tezani, em seu artigo sobre nativos digitais comenta que os nossos alunos estão imersos num contexto digital. Inseridos em uma sociedade digitalizada na qual as TDICs estão presentes na organização e no funcionamento da vida cotidiana. Indagamos sobre seu uso no processo de ensino e aprendizagem: "Como (re)pensar a prática pedagógica diante das especificidades dos nativos digitais?" (TEZANI, 2017, p.61).

O cenário atual, em que os alunos são nativos digitais, a utilização das TDICs como práxis inovadoras de interatividade nos faz refletir acerca da importância de proporcionar 
aos estudantes um ambiente inovador, uma vez que eles estão inseridos diariamente neste contexto das tecnologias.

O termo 'TDIC' tem como significado Tecnologias Digitais de Informação e Comunicação, e a sua aplicação como ferramentas pedagógicas no qual proporcionam aos professores liberdade para criar um ambiente favorável ao protagonismo dos estudantes, permitindo assim a interação, oportunizando o compartilhamento de experiências prévias e estimulando a criatividade. A possibilidade do uso das TDICs deve ser vista como elemento integrador na relação professor e aluno, desmistificando que o uso delas diminua a ação do docente, pelo contrário, quando bem aplicada, estreitamos ainda mais essa relação, pois o aluno é estimulado a interagir e protagonizar seu próprio aprendizado.

Diante dos desafios, é necessário que o docente esteja preparado para utilizar as TDICs, e ao elaborar seu plano de aula relacione os conteúdos a serem desenvolvidos às aplicações práticas de metodologias ativas de aprendizagem associadas ao uso das ferramentas digitais. Além de contribuir para a efetividade das aulas, dando maior sentindo ao processo de aprendizagem, o uso das metodologias ativas com as ferramentas tecnológicas aproxima o professor do universo dos seus alunos, devido à forma lúdica, criativa e alinhada às necessidades tecnológicas do século XXI.

Atualmente as TDICs estão sendo implementadas não só na modalidade presencial, mas também nos sistemas de educação a distância para enriquecer as atividades pedagógicas, tornando um grande desafio para muitos profissionais da área de educação.

De acordo com Piva Jr, Pupo, Gamez e Oliveira (2011, p.14) a educação a distância ganhou força no mundo todo e deixou de ser um espaço virtual independente e "cedeu lugar a um modelo educacional baseado em teorias de aprendizado colaborativo, teoria da cognição social, construção partilhada do conhecimento, inteligência coletiva, aplicação à EAD das teorias construtivistas e sociointeracionista, cuja ênfase no contexto social do aprendiz representa um papel determinante para aprendizagem".

Para conseguir alinhar o uso correto das TDICs especificadas acima com um ambiente virtual aprendizagem foi escolhida como exemplo a plataforma chamada Moodle, por proporcionar uma diversidade de ferramentas que podem ser trabalhadas junto com as TDICs externas que são utilizadas na modalidade presencial para facilitar a proposta pedagógica selecionada pelo professor na EaD.

Essa questão tem sido reforçada em estudos que diz que é preciso incentivar o uso de TICs na EaD como uma inovação na aprendizagem, pois "permite um acompanhamento de forma avaliativa, formativa e somativa, além de manter a memória virtual das interações" e "detém mais controle sobre suas atividades realizadas dentre do ambiente virtual". (BATISTA; ANTUNES, 2017).

\subsection{Educação a distância no MOODLE}

O Moodle é sistema modular de ensino a distância orientado a objetos, conhecido como ambiente virtual de aprendizagem (AVA), de código aberto, gratuito, livre de licenças e, que foi desenvolvido por Martin Dougiamas para apoiar a aprendizagem e facilitar a administração de cursos oferecidos na modalidade a distância (EaD). É a plataforma mais popular com cerca de $70 \%$ dos clientes do mundo inteiro, possui uma das maiores comunidades de desenvolvedores e programadores para fazer melhorias no código fonte do sistema, é patrocinada por mais de 80 empresas internacionais, possui mais de 200 milhões de usuários e foi traduzida para mais de 120 idiomas. 
De acordo com Rodolfo Nakamura, o Moodle também é conhecido como Sistema Gerenciamento de Aprendizagem (SGA) com foco na aprendizagem colaborativa, foi construído baseado na teoria socioconstrutivista, com atividades sociais que permitem construir artefatos como textos, imagens e vídeos, para que outros usuários visualizem e participem.

Vygotsky enfatiza como a cultura e a interação social estão envolvidas no desenvolvimento da consciência humana. Três temas sobrepostos unificam a ampla teoria de Vygotsky: eles lidam com a importância da cultura, o papel da linguagem e a relação entre aluno e professor. (LEFRANÇÓIS, 2019, p.254).

Possui diversas ferramentas que estimulam a participação dos alunos ativamente dentro das salas de aulas virtuais de acordo com os conteúdos propostos pelos professores e tutores. É considerada uma plataforma flexível e pode se adequar conforme as exigências das instituições de ensino. Imani e Joel (2017) fazem uma análise com uso de ferramentas e seus respectivos desempenhos no Moodle e com essas estratégias adotadas é possível melhorar o uso de ferramentas que estimulam a interação para minimizar os impactos negativos do distanciamento físico.

Além de ser completa pedagogicamente, também atende todas as normas técnicas de segurança da informação sendo considerada a plataforma de ensino mais confiável do mercado. Oferece a responsividade para todos os dispositivos móveis e sistemas operacionais. Disponibiliza ferramentas, recursos de extensão, documentação, cursos, conteúdos e plugins (módulos ou programas rápidos e leves) que são desenvolvidos por demanda e usados para promover funcionalidades específicas.

Conforme citado anteriormente, existem diversas tecnologias digitais de informação e comunicação (TDICs) disponíveis no mercado que podem ser trabalhados juntamente com o Moodle e que engloba um conjunto de mídias e tecnologias. As tecnologias digitais são equipamentos físicos chamados de hardwares que podem ser tablets, celulares, computadores etc. As mídias digitais são elementos lógicos pertencentes aos softwares que podem ser chamados também de arquivos etc.

Introduzindo as TDICs nos ambientes virtuais de aprendizagem é possível dinamizar os conteúdos, realizar atividades diferenciadas, despertar o interesse do aluno, promover a inclusão, evitar a evasão, melhorar o processo de ensino e aprendizagem, estimular a criatividade, trabalhar com a gamificação e muito mais. É importante ressaltar que o saber deve ser coeso e que cabe ao professor e à escola pensar em modelar uma metodologia na qual a interdisciplinaridade seja um instrumento para se alcançar uma visão integrada do mundo, qualquer que seja a disciplina. A avaliação pressupõe esforços anteriores de adoção de tecnologias, interdisciplinaridade e metodologias, num esforço coletivo, progressivo e contínuo de alcançar o patamar no qual cada aluno aprende.

A interdisciplinaridade surge "como uma possibilidade de romper os limites inerentes à divisão em disciplinas, propondo diversos níveis de integração do conhecimento" (MOUSINHO, 2018, p.1). Fazenda (2011) afirma que a interdisciplinaridade "não é uma categoria de conhecimento, mas sim de ação", portanto podemos nos referir à Interdisciplinaridade como uma atitude nova perante do ato de conhecer.

De acordo com Umbelino e Zabini (2014, p.6) a interdisciplinaridade tem como objetivo "englobar o máximo de disciplinas que possam contribuir com o conteúdo a ser desenvolvido com determinada turma, além de despertar na comunidade escolar um trabalho conjunto, possibilitando uma visão holística dos conteúdos partindo do conhecimento prévio do aluno".

Da mesma forma, visa a promoção de momentos de formação conjunta e de planejamento coletivo, envolvendo todos da equipe da Instituição de ensino (dirigente, coordenadores, supervisores, professores etc.), para que se possa, por meio do compartilhamento constante da concepção de educação e de estratégias de concretizá-la, efetivar a apropriação na prática. (XAVIER, 2020) 
Há um mundo e infinitas ferramentas que surgem a cada dia disponíveis dentro e fora do Moodle que podem ser trabalhadas, que podem ser utilizadas como metodologias ativas e serão apresentadas na etapa inicial do presente artigo.

\section{METODOLOGIA}

Visando alcançar melhorias na EaD e tornar os conteúdos didáticos estáticos em ambientes atrativos, interativos e dinâmicos para atender as exigências da geração atual de nativos digitais que estão sempre "conectados", houve-se a necessidade de implementar tecnologias digitais em um curso a distância e registrar a experiência adotada através da aplicação de um questionário no final do processo.

O público-alvo foi uma turma com 39 alunos do ensino superior, na faixa etária entre 24 e 30 anos, inscritos no curso de bacharel em educação física, pertencentes ao módulo composto com aulas $100 \%$ on-line, em uma instituição de ensino pública federal e que teve seu nome preservado. Esses alunos participaram dos cursos que tiveram a introdução de TDICs com metodologias ativas nos ambientes virtuais e também com experiências em outros cursos virtuais similares na mesma plataforma sem as TDICs.

A implementação das estratégias pedagógicas e tecnológicas no módulo do curso iniciou no $1^{\circ}$ semestre de 2020 e teve a duração de seis meses. Foi criado um questionário na ferramenta chamada "Pesquisa" disponível somente no Moodle, aplicado ao final do curso no $2^{\circ}$ semestre de 2020 e disponível para os alunos durante 1 (um) mês, devido as atividades na EaD serem assíncronas.

A atuação dos autores foi significativa para área educacional despertando a necessidade de se aprofundar no assunto para o enriquecimento do presente artigo científico. É necessário que a experiência adotada fique registrada como base de consulta e apoio para outras universidades e escolas.

\subsection{Etapas da metodologia}

Para atingir os objetivos propostos e explicar com clareza todo o desenvolvimento do presente artigo para os leitores, o projeto foi desenvolvido por etapas, para detalhar a experiência vivenciada nos ambientes virtuais no intuito de realizar as melhorias, com o uso de metodologias ativas e TIDCs na EaD.

A primeira etapa foi um planejamento baseado em um aprofundamento com leituras em bibliografias e artigos para a fundamentação teórica, testes e usabilidade das ferramentas digitais instaladas com metodologias ativas na modalidade EaD.

A segunda etapa também foi importante para a realização de um questionário ao público-alvo no final do curso, com perguntas abertas e fechadas e análise dos resultados da pesquisa para verificar se eles foram suficientes. 
Figura 1 - Demonstram as etapas iniciais do projeto e etapas finais da aplicabilidade do questionário.

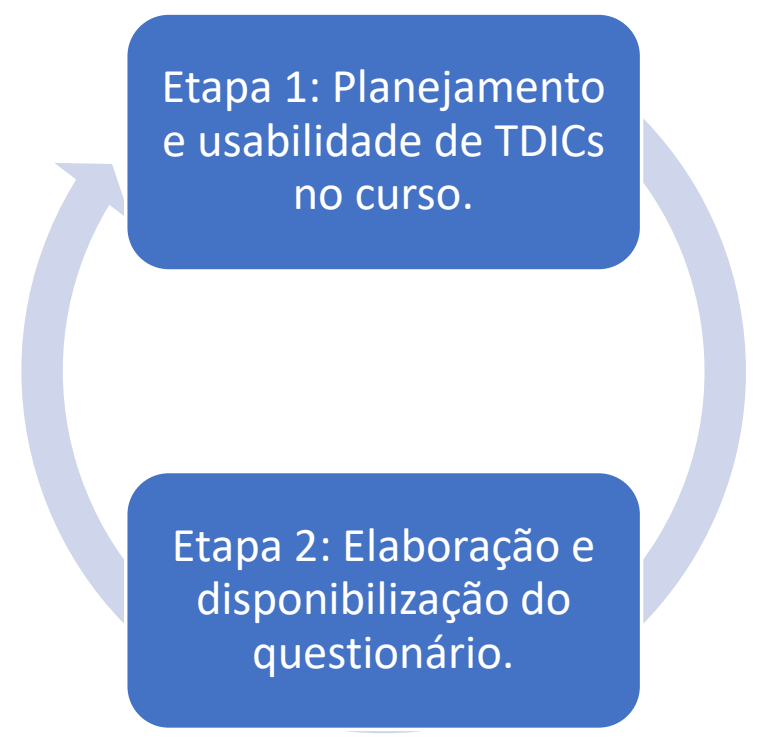

Fonte: Próprios autores (2021).

\subsubsection{Primeira etapa}

Para planejar e enriquecer a primeira etapa foram realizadas leituras de publicações de artigos científicos recentes, conversas informais com profissionais da área de informática e educação, consultas em bibliografias famosas de autores especializados na educação a distância, inscrições em cursos e canais do YouTube, acessos em textos de sites confiáveis, testes de softwares e questionário no AVA para se ter um feedback das experiências adotadas.

Após o processo de conhecimento e aprofundamento das melhores práticas pedagógicas e tecnológicas foram selecionadas as tecnologias compatíveis com as metodologias ativas que são ferramentas que estimulam a interação, proporcionam motivação e o engajamento dos alunos.

No primeiro dia de aula, os alunos tiveram acesso as TDICs implementadas e configuradas de acordo com a proposta pedagógica, sendo apresentados o PLADIS da disciplina, ambientação, conteúdos didáticos com as atividades e questionários, diferentemente dos outros cursos oferecidos nos anos anteriores, em que só existiam arquivos em PDFs para leituras e questionários.

Abaixo, encontram-se as figuras com as interfaces do ambiente virtual Moodle com as tecnologias adicionadas nos cursos atuais. A figura 2 é o curso do ano anterior sem o uso de metodologias ativas e TDICs. A figura 3 é o curso do ano atual com a implementação de TIDCs, com interação e metodologias ativas. A figura 4 também representa o curso atual demonstrando o uso de uma ferramenta de "webconferência" também considerada uma TDICs chamada BBB dentro do AVA Moodle. A figura 5 representa o uso da ferramenta externa conectada ao site de jogos digitais que está fora do ambiente Moodle.

Todas as TDICs foram utilizadas pelos alunos com o uso de metodologias ativas nos espaços virtuais, mas é importante ressaltar, que a forma como toda esta grandeza é utilizada em prol do saber do aluno, precisa ser aplicada corretamente pelo professor que deve adotar estratégias pedagógicas que façam associação entre o conteúdo e a tecnologia para gerar insumos que alimentam o ensino-aprendizado. 
Figura 2 - A figura 2 foi exportada do ambiente virtual de aprendizagem (AVA) da instituição de ensino que teve sua identidade preservada, de um curso do ano anterior que não teve o uso de TDICs e apenas 1 fórum de apresentação no qual não houve interação em que o aluno não foi o protagonista dentro do Moodle.

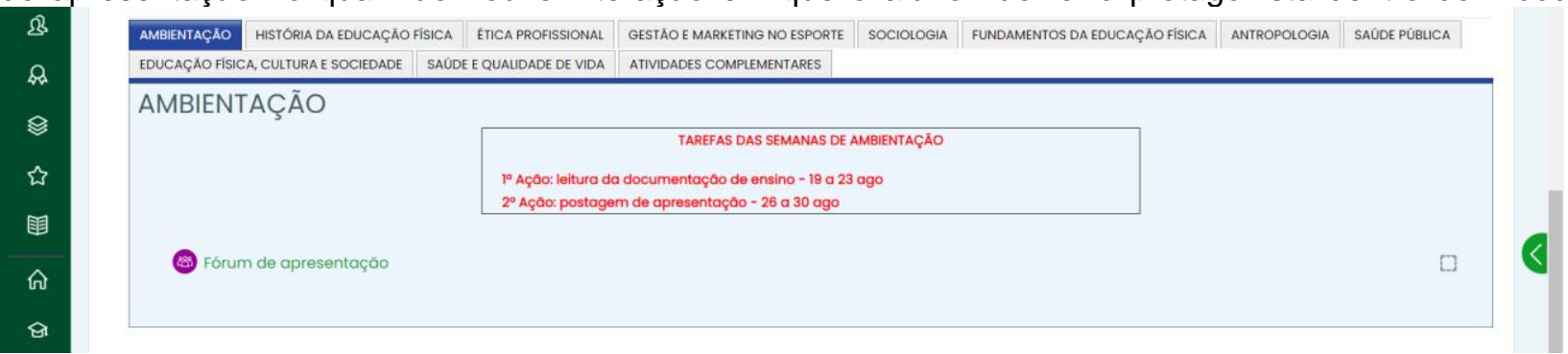

Fonte: Próprios autores (2021)

Figura 3 - A figura 3 foi exportada do ambiente virtual de aprendizagem (AVA) da instituição de ensino que teve sua identidade preservada, no uso de TDICs como "videoaulas" e "fóruns de interação" com estratégias pedagógicas em metodologias ativas utilizando ferramentas internas e externas dentro do Moodle.

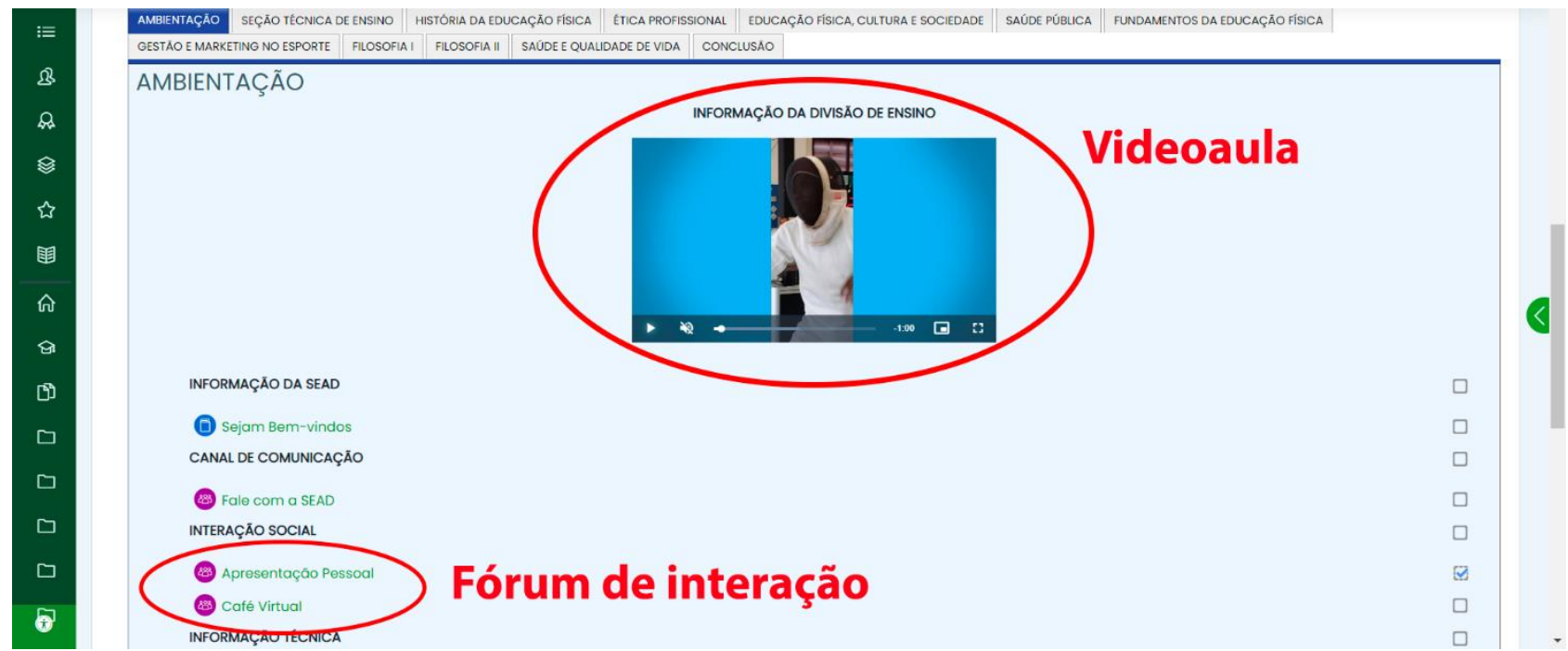

Fonte: Próprios autores (2021)

Figura 4 - A figura 4 foi exportada do ambiente virtual de aprendizagem (AVA) da instituição de ensino que teve sua identidade preservada, no uso de TDICs de webconferência chamada "BBB" com estratégias pedagógicas em metodologias ativas utilizando ferramenta interna do Moodle.
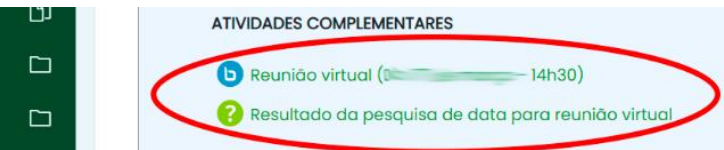

\section{Webconferência}

Fonte: Próprios autores (2021) 
Figura 5 - A figura 5 foi exportada do ambiente virtual de aprendizagem (AVA) da instituição de ensino que teve sua identidade preservada, no uso de TDICs do tipo gamificação chamada "URL Externa" com estratégias pedagógicas em metodologias ativas utilizando ferramenta interna do Moodle.

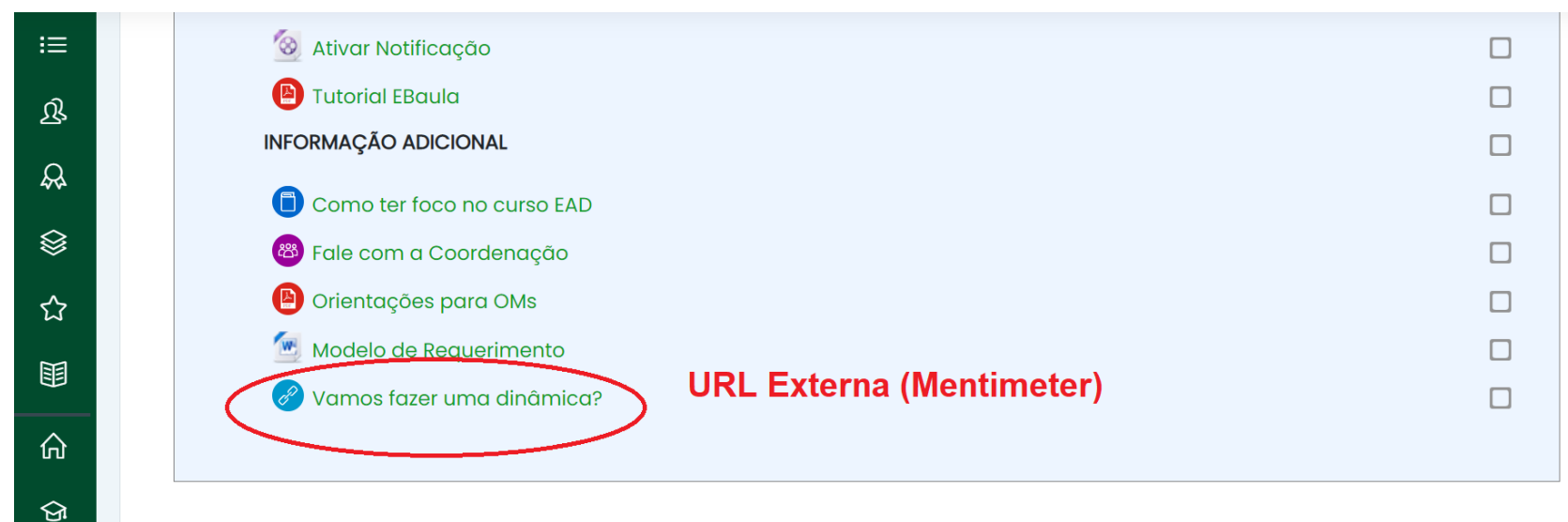

Fonte: Próprios autores (2021)

A videoconferência é um recurso utilizado atualmente para auxiliar o ensino remoto e tem o objetivo de fazer reuniões on-line e bate-papo entre professores e alunos, mas também podem ser utilizadas na EaD, visto que os encontros remotos ficam salvos automaticamente ou manualmente no ambiente virtual e passa a ser uma atividade assíncrona. As ferramentas externas mais comuns de videoconferência, ou seja, que estão fora do ambiente Moodle são: o Zoom, Google Meeting e Microsoft Teams. Existem também as internas que estão dentro do Moodle, usadas para a mesma finalidade que é o BBB (BigBlueButton). O BBB do Moodle (BigBlueButton) é um recurso de webconferência que oferece compartilhamento de áudio, vídeo, arquivos de texto, quadro branco, desenhos, ponteiro, chat público ou privado, salas de descanso e com extensão para arquivos para Microsoft Office documentos.

A ferramenta Chat que também está em voga é o WhatsApp, que é um aplicativo de mensagens escritas e voz instantâneas para qualquer dispositivo e sistema operacional que permite o envio de imagens, vídeos, arquivos PDF etc. O chat do Moodle é uma ferramenta de interação textual no qual todos se comunicam em tempo real, que podem ser disponibilizados pelos professores com data e hora agendadas.

Os vídeos e slides dinâmicos, por exemplo, são mídias digitais utilizadas no ensino presencial com o uso de projetor ou Datashow dentro das salas de aula e que também podem ser trabalhadas na modalidade EaD. Eles podem ser produzidos com auxílio de câmeras fotográficas, webcams ou celulares, que também são considerados TDICs e importados facilmente para plataforma Moodle. Os slides é um termo técnico usado nos programas do PowerPoint da empresa Microsoft e Impress do LibreOffice. Esse recurso também pode ser oferecido na web através do termo Slideshow. Ambos também podem ser salvos e importados através da ferramenta chamada "Arquivos" no ambiente virtual de aprendizagem Moodle. Essa ferramenta permite que o professor forneça arquivos de diversos formatos para compartilhar apresentações, programas de software para que os estudantes possam trabalhar com edição etc.

Uma outra ferramenta interna do Moodle chamada "URL" ou "Ferramenta Externa" permitem a inserção de link da web para qualquer página que esteja disponível on-line como por exemplo Padlet, Kahoot, Mentimeter, Flickr, YouTube, Wikipédia etc. Essas ferramentas podem ser utilizadas para importar atividades com gamificação promovendo a interação, desenvolvimento de raciocínio lógico, habilidades tecnológicas, emocionais e cognitivas. O Kahoot é uma plataforma on-line intuitiva, desenvolvida para trabalhar com 
conteúdos educacionais através da gamificação podendo ser utilizada em qualquer dispositivo tecnológico. O Mentimenter é uma ferramenta on-line que serve para mensurar e ilustrar os resultados sinalizados pelos estudantes, de acordo com a temática apresentada pelo professor. O Padlet viabiliza a criação de um quadro interativo e virtual permitindo a organização dos conteúdos e utilizados para mapeamento mental. Essas ferramentas de gamificação são gratuitas e também podem ser facilmente importadas para o Moodle.

Existem as ferramentas internas mais tradicionais que também podem ser utilizadas para promover a interação, como, por exemplo, envio de trabalhos em grupos de alunos através da ferramenta chamada "Tarefas" e "Páginas" em que permite criar um recurso de página da web utilizando o editor de texto com conteúdos personalizados, resumo do programa do curso, vídeos, som, texto, imagens, links da web, Google Mapas e código incorporado.

\subsubsection{Segunda etapa}

A segunda etapa foi importante para elaboração da pesquisa baseada nas inquietações iniciais que foram detalhadas e registradas as experiências adotadas. A seguir serão apresentados os detalhes da pesquisa para análise do resultado, e lembrando que não serão todas as questões analisadas.

O cenário dos métodos foi executado ao final do módulo de uma turma do curso oferecido, conforme o perfil especificado anteriormente, na modalidade EaD, na ferramenta chamada "Pesquisa" dentro do próprio Moodle, do tipo ATTLS, com foco no construtivismo social em interação para entender a percepção e sugestões dos alunos.

A Pesquisa foi disponibilizada no mesmo local onde foram oferecidos os novos cursos que tinham as ferramentas implantadas, instaladas e testadas como tecnologias digitais da informação e comunicação no ambiente virtual de aprendizagem.

A participação para os alunos na pesquisa foi configurada como não obrigatória, de forma voluntária, anônima para o público externo, com acesso identificado no sistema apenas para o autor e com questionário configurado com preenchimento obrigatório, proporcionando também a possibilidade de o participante marcar como resposta a opção "não sei responder".

A pesquisa foi qualitativa para formalizar e compreender os fenômenos explorados em prol da boa qualidade na educação. Foram inseridas sete perguntas com questões objetivas e três perguntas com questões subjetivas. Diante do questionário lançado, são destaques duas perguntas principais e determinantes para o resultado do presente artigo.

A coleta de dados foi realizada, analisada, tratada e preservada de acordo com o termo de esclarecimento, armazenados no banco de dados do Moodle e de posse dos pesquisadores por um período de cinco anos mantendo a integridade dos dados e informações geradas. Todas as normas de segurança foram implementadas com o controle de acesso através de login e senha, bloqueios para qualquer tentativa de alteração e repetição, e com registros de logs ativados.

Todos os protocolos éticos foram seguidos durante a pesquisa tendo em vista o público-alvo. No texto do termo de esclarecimento, constava um convite para o aluno participar da pesquisa não obrigatória, identificada para o pesquisador e anônima para o público externo. 
Ao responder a pesquisa, o aluno estava de acordo com TCLE: A Comissão Nacional de Ética em Pesquisa (Conep) orienta pesquisadores e Comitê de Ética em Pesquisa em relação a procedimentos que envolvam o contato com participantes e/ou coleta de dados em qualquer etapa da pesquisa, em ambiente virtual. Tais medidas visam preservar a proteção, segurança e os direitos dos participantes de pesquisa. (Resoluções do Conselho Nacional de Saúde - CNS - nº. 466 de 2012 e a de nํ. 510 de 2016) e (Dados pessoais: informação relacionada à pessoa natural identificada ou identificável artigo 5ำ da Lei Geral de Proteção de Dados - LGPD - n‥ 13.709, de 14 de agosto de 2018).

Figura 6 - A figura 6 foi exportada do ambiente virtual aprendizagem (AVA) da instituição de ensino que teve sua identidade preservada no uso da ferramenta chamada "Pesquisa" disponível no Moodle.

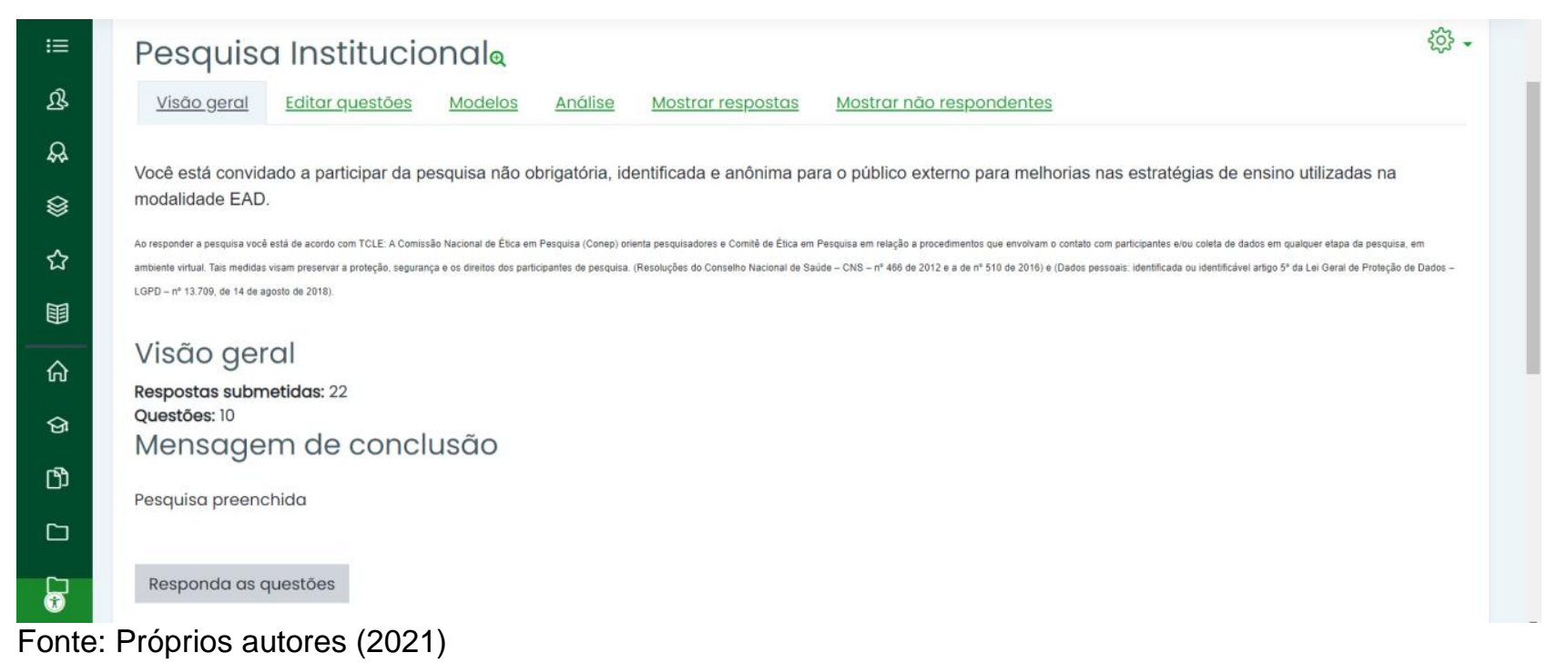

Fonte: Próprios autores (2021) 
Figura 7 - A figura 7 foi exportada do ambiente virtual aprendizagem (AVA) da instituição de ensino que teve sua identidade preservada demonstrando todo o questionário aplicado para coleta de dados.

\section{Pesquisa Institucional}

Modo: O nome do usuário será registrado e mostrado com as respostas

Como você avalia o seu próprio interesse e participação nas disciplinas cursadas? (1)

O Não selecionado

Oxcelente

Muito bom

Bom

ORegular

Não sei responder

Qual nota você daria para a sua própria dedicação na fase EAD (Dê uma nota de 0 à 10)?(1)

O Não selecionado

Nota 10 (Me considero um excelente aluno)

Nota 8 ou 9 (Me considero um bom aluno)

Nota 6 ou 7 (Me considero um aluno mediano)

Nota 5 ou < (Me considero um aluno com dificuldades)

Não sei responder

Como você avalia de uma forma geral o conteúdo das disciplinas?(1)

Não selecionado

Excelente

Muito bom

Bom

Regular

Não sei responder

Como você avalia as avaliações somativas?(1)

O Não selecionado

Excelente

Muito bom

Bom

Regular

Não sei responder

Como você avalia de uma forma geral a plataforma EAD a nivel técnico? (1)

Não selecionado

Excelente

Muito bom

Bom

Regular

Não sei responder 


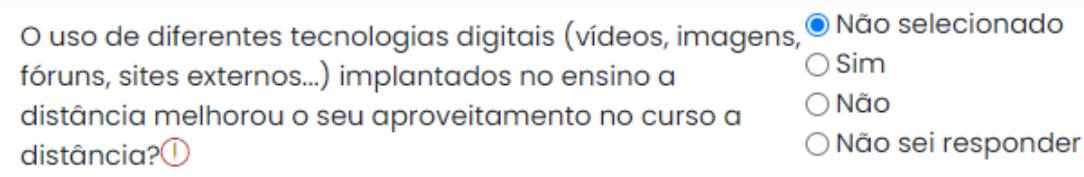

Descreva que tipos de tecnologias digitais da informação e comunicação(TDICs) você gostaria de encontrar no ensino a distância?(1)

As estratégias de humanização(ex: vídeos dos chefes, boas-vindas, ambientação, acolhimento, encerramento, café virtual, espaço de apresentação pessoal, atendimento pelo chat, email, whatsapp...) utilizadas no ensino a distância foram importantes $p /$ você?(1)

Descreva como sugestão outras técnicas de humanização que você tenha vivenciado em outro curso a distância:(1)

Escreva aqui a sua sugestão para melhorias na $2^{\alpha}$ fase EAD:(1)

Fonte: Próprios autores (2021)

Recentemente o neurocientista Michel Desmurget publicou o resultado de um estudo realizado na geração $Y$ que nasceram junto com a tecnologia chamados de "nativos digitais" e o resultado foi surpreendente, pois foi comprovado que o Q.I (Quociente Intelectual) dessa geração está mais baixo que a geração anterior. Pertencer ao grupo da geração $Y$ não significa que ao longo de suas vidas utilizaram a tecnologia de maneira correta para o desenvolvimento cerebral, por isso é importante destacar que o uso de ferramentas tecnológicas aliadas as estratégias pedagógicas são fundamentais para reverter e melhorar o aumento do Q.I da atual geração.

Para o futuro ainda é preciso muitos estudos específicos para a sociedade contemporânea não rotular a tecnologia na educação como algo prejudicial, pelo contrário, é preciso usar a tecnologia a favor da educação. A atual geração não pode repetir os mesmos erros das gerações anteriores, que não souberam aproveitar os recursos digitais como aliado no crescimento intelectual. 


\section{ANÁLISE E DISCUSSÃO DOS RESULTADOS}

Os resultados das pesquisas e a interpretação aos achados encontrados no estudo foram satisfatórios, a princípio os resultados foram esperados e não houve a necessidade de realizar novas pesquisas. Os detalhes e as figuras serão apresentados abaixo com as análises e discussões mais relevantes a fim de demonstrar a eficácia do planejamento e do trabalho realizado ao longo dos últimos meses na turma do curso em EaD, utilizando as metodologias ativas com as novas tecnologias digitais de informação e comunicação (TDICs) como instrumento na prática.

\subsection{Primeira etapa}

Andrea Filatro explica em seu livro chamado Produção de Conteúdos Educacionais, que as tecnologias fascinam o usuário, facilita a vida de todas as pessoas, abrem novas perspectivas na produção individual e coletiva, e nos convida a acompanhar a constante evolução tecnológica no ramo educacional que abrirá um mundo inimaginável de aprendizagem. As novas tecnologias, juntamente às novas mídias, representam um acréscimo de possibilidades de aprendizagem (FILATRO, A; CAIRO, S; 2015, p.106).

Depois de inúmeras análises realizadas foi averiguado que 0 melhor recurso tecnológico que poderia ser implementado é a videoaula, que é uma tecnologia digital da informação e comunicação (TDIC) externa, produzida fora do ambiente Moodle e depois importada para sala de aula virtual capaz de reter a atenção do aluno.

O uso também de outra TDIC chamada webconferência é uma ferramenta interna e disponível dentro do ambiente Moodle que também possui os mesmos benefícios da videoaula, porém com um grande atrativo que é a interação em tempo real, pois permite que os estudantes sejam espontâneos e participativos, fazendo com que o aluno seja 0 protagonista da aula no uso de metodologias ativas.

A implantação da TDIC interna chamada "fórum", também está disponível no Moodle sendo capaz de promover debates coletivos para construção do conhecimento e fixação do conteúdo.

Após alguns meses de implantação de TDICs, videoaulas, fóruns, webconferências, gamificação, chat e atendimento individualizado por rede social, a instituição recebeu inúmeros elogios de forma espontânea de professores e tutores especialistas na área de educação.

As observações feitas durante aplicação das TDICs no decorrer das aulas demonstraram que os alunos ficaram engajados e promoveram a participação em massa trazendo a perspectiva das metodologias ativas para o ensino a distância.

Metodologias ativas são estratégias de ensino centradas na participação efetiva dos estudantes na construção do processo de aprendizagem, de forma flexível, interligada e híbrida. Num mundo conectado e digital, elas se expressam por meio de modelos de ensino híbridos, com muitas possíveis combinações. A junção de metodologias ativas com modelos flexíveis e híbridos traz contribuições importantes para o desenho de soluções atuais para os aprendizes de hoje. (BACICH; MORAN, 2018).

\subsection{Segunda etapa}

Foi realizada a coleta de dados e análise dos resultados da pesquisa disponibilizada para o público-alvo com o objetivo de verificar se eles foram eficientes, suficientes e 
importante para o registro da aplicação das tecnologias e experiências adotadas na base de dados.

O quantitativo de participantes que responderam o questionário foi 22 em uma turma com total de 39 alunos e os outros 17 alunos da mesma turma optaram em não responder a pesquisa.

Os resultados das pesquisas foram esperados e satisfatórios, e não houve a necessidade de realizar novas pesquisas.

Após uma análise no questionário com as suas respectivas respostas, duas perguntas importantes foram selecionadas como destaque no presente artigo sobre o uso de TDICs e metodologias ativas, pois retratam especificamente do uso das tecnologias digitais. Lembrando que não serão todas as perguntas analisadas, e sim, apenas, as mais evidenciadas e relevantes.

Foi realizada a seguinte pergunta objetiva sobre o uso de TDICs "O uso de diferentes tecnologias digitais (vídeos, imagens, fóruns, sites externos...) implantados no ensino a distância melhorou o seu aproveitamento no curso a distância?". Todos marcaram a opção "sim", ou seja, todos afirmando que o uso de diferentes tecnologias digitais (vídeos, imagens, fóruns, sites externos, webconferências...) implantados no ensino a distância melhorou a aprendizagem colaborativa e o aproveitamento no curso a distância.

A outra pergunta importante foi do tipo discursiva, com respostas relevantes na pesquisa, no qual pedia para os alunos "Descrever que tipos de tecnologias digitais da informação e comunicação (TDICs) você gostaria de encontrar no ensino a distância". As respostas foram lidas, analisadas e interpretadas. Dos 22 participantes da pesquisa, 16 alunos responderam e reforçaram o que haviam respondido anteriormente na questão objetiva, que desejavam mais o uso de TDICs como videoaulas no ensino $\mathrm{EaD}$, dando outras sugestões de ferramentas que promovem a interação e mencionadas anteriormente.

Abaixo encontram-se os prints da interface dos resultados da coleta de dados aplicado no ambiente virtual de aprendizagem Moodle com o uso da ferramenta "pesquisa" conforme discriminado anteriormente.

Figura 8 - A figura 8 abaixo é o resultado da pergunta objetiva sobre se o uso de diferentes tecnologias digitais (vídeos, imagens, fóruns, sites externos...) implantados no ensino a distância melhorou o seu aproveitamento no curso a distância.

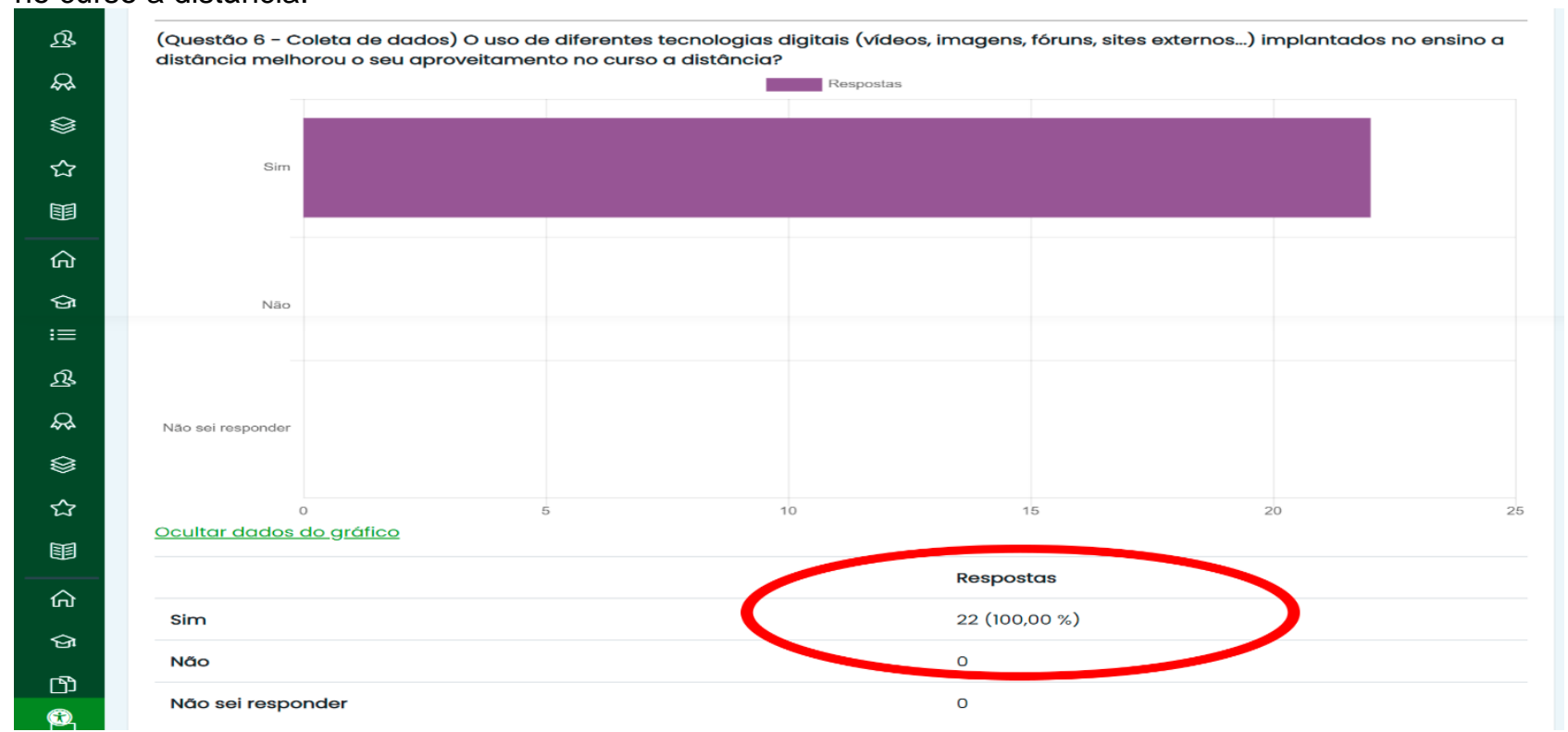

Fonte: Próprios autores (2021) 
Quadro 1 - Análise das respostas da questão discursiva selecionada da pesquisa implantada no ambiente virtual Moodle que tem maior relevância. Ressaltando que tiveram usuários que escolheram mais de 1 (uma) resposta.

\begin{tabular}{|c|c|c|c|c|c|c|c|}
\hline \multicolumn{1}{|c|}{16 dos 22 de alunos participantes da pesquisa escolheram quais tipos de TDICs } \\
gostariam de encontrar mais na EaD \\
\hline TDIC & Videoaula & Chat & $\begin{array}{c}\text { App msg } \\
\text { instantânea }\end{array}$ & Webconferencia & $\begin{array}{c}\text { Slide } \\
\text { dinâmico }\end{array}$ & Fórum & $\begin{array}{c}\text { Site } \\
\text { externo }\end{array}$ \\
\hline $\begin{array}{c}\text { Quant/ } \\
\text { alunos }\end{array}$ & 12 & 1 & 1 & 2 & 2 & 3 & 1 \\
\hline
\end{tabular}

Fonte: Próprios autores (2021).

Figura 9 - A figura 9 abaixo é o resultado da pergunta subjetiva pedindo para o aluno descrever que tipos de tecnologias digitais da informação e comunicação (TDICs) gostaria de encontrar no ensino a distância?

(Questāo 7 - Coleta de dados) Descreva que tipos de tecnologias digitais da informação e comunicaçāo(TDICs) você gostaria de encontrar no ensino a distância?

- Vídeos

- Acho que com videos e fotos, o objetivo foi atingido

- Mais vídeos tratando dos assuntos ministrados, de maneira a fornecer demonstrações e opiniōes acerca do assunto, o que facilitaria na elucidação dos conteúdos. O simples e puro conteúdo textual não é uma maneira completa de abordar os assuntos.

- Aula por video conferência

- Acredito que as tecnologias utilizadas suprem as minhas necessidades, material escrito e vídeos foram o suficiente.

- Eu gostaria de encontrar plataformas que permitissem acesso aos conteúdos por diferentes meios (tablet e celular, por exemplo). Além disso, em relaçāo à comunicação, esperava encontrar vídeos dos conteúdos tratados. Todas as expectativas foram atendidas no EAD cursado!

- Indicar vídeos no youtube que falem sobre o assunto.

- Criação de um grupo de whatsapp para retirada de dúvidas, tanto sobre a plataforma quanto as aulas.

- Vídeos, imagens, artigos em pdf e as próprias aulas preparadas pelos instrutores.

- Todos que eu gostaria foram aplicados neste EAD

- Nada a declarar.

- Seria muito interessante que a plataforma de EAD continuasse propondo as atividades que acontecem atualmente, como os vídeos e disponibilidade de artigos e interação com os instrutores.

- Seria interessante mais vídeos que abordem as matérias do curso.

- video aula do professor explicando sobre a matéria. tiragem de dúvidas nos fóruns.

- videos e slides

- Se possível chat direto com os instrutores das matérias

- Questionários digitais. Video aulas gravadas.

- As que foram empregadas foram suficientes para bom entedimento e comunicação.

- Videoconferência

- Na minha opinião, poderia ter mais vídeos sobre os conteúdos, pois há uma melhor fixação dos conhecimentos ao assisti-los após a leitura dos textos.

- Năo vejo outras.

- 1. Vídeos

2. Slides dinâmicos.

3. Foruns

Fonte: Próprios autores (2021) 
Analisando as respostas subjetivas, observamos e concluímos sobre a importância de processos dialógicos de avaliação, nos quais o ato de medir o impacto de algo sobre nós, sugere a importância de antecipar as consequências da interação sobre nosso ser integral. É preciso saber de que forma o aluno aprende, é preciso conceber formas de ensinar que o levem de forma gratificante a memorizar e a estender o conhecimento, produzir seus próprios caminhos de aprendizagem.

Tanto a escola quanto o professor têm que ouvir, ler o universo de compreensão do aluno, que é posto por ele no papel, nos fóruns, nos diálogos, em suas respostas. Uma ferramenta de avaliação ajuda nesta tarefa, seja um instrumento de inteligência artificial conversacional, um sistema embutido no Moodle ou uma simples conversa no corredor ou durante uma aula remota. É preciso avaliar como o aluno aprende e isto só ele pode saber e dizer. A inferência pedagógica docente neste momento precisa ser substituída pela presença atenta e avaliativa do professor ou professora. A avaliação simboliza o momento da leitura dos significados que o aluno empresta a tudo que faz.

Hoje sabe-se que os processos cognitivos são ativados externamente a partir das interações com o meio ambiente, local em que estão as novas tecnologias digitais. No entanto, cada aluno ou aluna é um mundo de vivências, de histórias, de segredos que só podem ser desvendados se o professor perceber como o discente aprende.

É fundamental para o ensino-aprendizado ousar conhecer os processos enativos individuais, o recôndito do ser do aluno/aluna, que os leva no mundo exterior a existir como um ser único e original. Qual é a percepção que o aluno tem daquilo que está aprendendo, de que forma a bagagem que possui, sua história pessoal filtram, aclaram, moldam o que ele está ouvindo, lendo, aprendendo?

Esta é a finalidade da educação, tornar cada aluno um portador da luz do conhecimento e para contribuir nesta jornada, apresentamos uma ferramenta de avaliação no Moodle, que através de um diálogo simples estimula o desenvolvimento de uma percepção voltada ao diverso mundo de significados que levam ao aprendizado.

Ao analisar as respostas da figura 9 vemos os processos enativos em ação, o diverso mundo de cada um com suas experiências e é a partir deste cume, que podemos mudar as metodologias, os métodos, as tecnologias que empregamos em sala de aula. Sem a percepção dos processos enativos, o desenvolvimento das habilidades cognitivas fica comprometida e reduzida a um aprendizado bancário, como diria o eminente professor Paulo Freire.

\section{CONSIDERAÇÕES FINAIS}

Chegamos ao final do século XIX, com a necessidade de reorganização das práticas educacionais chamadas de Movimento da Escola Nova, iniciado mediante as críticas e questionamentos ao ensino tradicional, uma vez que o referido método não acompanhava as necessidades que surgiam com o fortalecimento da industrialização e impulsionada pelos avanços tecnológicos da Primeira Revolução Industrial. Na Era Digital também conhecida como Era Tecnológica, já no final do século XX aprofundaram-se as reflexões acerca de repensar a prática de ensinar, já que o modelo tradicional tinha base na exposição dos conteúdos, condicionando o aluno ao uso de tecnologias reprodutíveis como televisão, rádio, jornal, entre outras.

Assim, nos últimos anos, a educação brasileira veio passando por grandes transformações devido ao surgimento de novas tecnologias e metodologias. Em consequência disso, foram discutidas novas estratégias de ensino capazes de melhorar a 
aprendizagem em um mundo tão dinâmico e em um meio de uma grande revolução em que as informações não param de crescer.

Aprender está diretamente relacionado com a capacidade de despertar e estimular no aluno as habilidades intelectuais, sendo motivados pela ação pedagógica inovadora, que estimula o uso das TDICs e desperta a vontade de aprender a partir das tecnologias de informação e comunicação.

A revisão dos artigos e bibliografias estudadas apresentou comprovações de que as tecnologias digitais externas disponíveis na internet são tão eficientes para o ensino quanto as ferramentas internas disponíveis no Moodle porque todas são capazes de despertar e estimular habilidades intelectuais dos alunos, sendo motivados pela ação. A criatividade do profissional no planejamento das aulas preconizando o uso das metodologias ativas e conciliada com a inclusão desses recursos tecnológicos, enriqueceu a proposta pedagógica das instituições de ensino com educação a distância.

Os pesquisadores do presente artigo estão trazendo uma metodologia de uma escuta atenta do aluno de como tornar as aulas mais agradáveis. Os resultados foram esperados e satisfatórios, a pesquisa foi suficiente e não há a necessidade de realizar novos experimentos. Foi possível constatar que os resultados obtidos por meio do questionário afirmam que os alunos querem sim novas tecnologias digitais e em maior quantidade. Eles querem mais interação, querem conversar com os professores, querem ouvir e ver a imagem do professor e querem que as TDICs sejam aplicadas nas aulas EaD com mais frequência para atender as suas reais necessidades. Os alunos querem aula dialógica, querem vídeos, fóruns, chats, webconferências, slides dinâmicos e muitas outras exigências. Essa pesquisa trouxe muitas informações sobre o que os nossos alunos esperam da instituição. As atuais mídias serão aperfeiçoadas, produzidas em uma quantidade maior e implementadas para os próximos anos.

A introdução de metodologias ativas e de tecnologias na educação também gerou uma grande repercussão positiva entre professores e tutores, pois todos foram elogiados pelo público interno e externo da instituição de ensino e logo todos se sentiram motivados para planejar e executar tarefas diferenciadas para os alunos de outras turmas. A etapa da organização da pesquisa foi composta pela prática no uso das ferramentas tecnológicas nas atividades pedagógicas propostas em algumas instituições de ensino e observou-se ao longo do desenvolvimento desse trabalho que muitos profissionais da área de educação não sabem utilizar e nem sequer conhecem tais ferramentas e tecnologias disponíveis para melhorar o ensino em EaD. Após análise da coleta de dados, as introduções das TDICs e metodologias ativas no ensino a distância foi motivador para os professores gerando um impacto positivo cibercultural.

Foram elaboradas questões com perguntas abertas discursivas e fechadas objetivas, que tiveram destaques nas análises porque os alunos deram como sugestão a implantação de outras novas TDICs internas e externas que gostariam de encontrar na plataforma que seriam videoaulas, slides dinâmicos, videoconferências e chats. É preciso inovar na educação, implantar as TDICs e diversificar de acordo com a tecnologia proposta para cada período aplicado.

Os testes de softwares realizados constataram que a plataforma Moodle é capaz de aceitar outras TDICs externas que não estão dentro do ambiente virtual proporcionando um "leque" de opções de escolhas para professores e tutores utilizarem dentro das salas virtuais. As TDICs externas como Mentimeter, Kahoot, Jamboard etc., estão programadas para gerar links ou arquivos digitais que podem, por exemplo, ser importadas dentro do Moodle de forma intuitiva e sem causar quaisquer transtornos. 
A continuidade desse trabalho visa realizar melhorias no sistema de educação a distância e demonstra o quanto é importante que novos estudos em Tecnologias Digitais da Informação e da Comunicação (TDICs) com metodologias ativas precisam ser constantemente aplicados, pois, nos próximos anos, muitas dessas tecnologias estarão obsoletas, necessitando de atualizações e até mesmo de substituições no Ambiente Virtual de Aprendizagem (AVA) Moodle.

Sugere-se também a elaboração de novas pesquisas para constatar a eficiência do uso de novas TDICs no Moodle ou em outras LMS (Learning Management System) que são Sistemas de Gestão da Aprendizagem ou outras práticas de metodologias ativas na EaD.

\section{REFERÊNCIAS}

ANJOS, $\mathrm{H}$ et al. As políticas públicas educacionais do município de Quixeramobim durante o isolamento social. RECITE- Revista Carioca de Ciência Tecnologia e Educação, Rio de Janeiro, v.5, n.2. 2020. DOI: https://doi.org/10.17648/2596-058X-recitev5n2-2. Acessado em: nov. 2020.

BATISTA, P. V. do C.; ANTUNES, J. T. O uso do ambiente virtual de aprendizagem moodle e de tics: percepção e experiência. UniMontes, 2017. Disponível em: www.ead.unimontes.br. Acessado em: nov. 2020.

CAMBI, F. História da pedagogia. São Paulo: Editora da UNESP, 1999.

Juliana dos Santos e Sandra Medeiros

EDUCLASS. Manual do Professor - Moodle. Disponível em https://educlass.com.br/moodle $/ \mathrm{mod} / \mathrm{book} / \mathrm{view} . \mathrm{php}$ ?id=1010\&chapterid=446. Acessado em: nov. 2020.

FILATRO, A.; CAIRO, S. Produção de conteúdos educacionais. 1.ed. São Paulo: Saraiva, 2015.

HORN, M. B.; STAKER, H. Blended: usando a inovação disruptiva para aprimorar a educação. Porto Alegre: Penso, 2015.

IMANI, M; JOEL, S. M. Using learning analytics to predict students' performance in moodle learning management system: a case of mbeya university of science and technology.

Electronic Journal of Information Systems in Developing Countries (EJISDC). 2017. Disponível em: https://onlinelibrary.wiley.com/doi/abs/10.1002/j.1681-4835.2017.tb00577.x . Acessado em: mar. 2021.

LEFRANÇÓIS, G. R. Teorias da aprendizagem: o que o professor disse. 6.ed. São Paulo: Cengage, 2019.

MANFREDINHO, N., P. de S. A Escola Secular de Hoje. Tecnologia \& Humanismo. início de uma nova etapa. Curitiba, CEFET-PR no 20. 2001.

MOODLE. Site do Moodle Disponível em: https://moodle.org/?lang=pt br. Acessado em: nov. 2020.

MORAIS, C. Metodologias ativas no EAD, como aplicar? In Blog Sponte. Pato Branco, PR. 2020. Disponível em: https://www.sponte.com.br/metodologias-ativas-ead-comoaplicar/. Acessado em: jun. 2021. 
NAKAMURA, R. Moodle: Como criar um curso usando a plataforma de ensino a distância. 1.ed. São Paulo: Farol do Forte Editora, 2008.

PIVA Jr, D.; PUPO, R.; GAMEZ, L.; OLIVEIRA, S. EAD na prática: planejamento, métodos e ambientes de educação online. Rio de Janeiro, Elsevier, 2011.

SANTOS, J. dos; MEDEIROS, S. EAD em Pauta. Disponível em http://eadempauta.com.br/metodologias-ativas-na-pratica-como-estimular-a-leitura/ . Acessado em: abr. 2021.

TEZANI, T. C. R. Nativos digitais: considerações sobre os alunos contemporâneos e a possibilidade de se (re) pensar a prática pedagógica. DOXA: Revista Brasileira de Psicologia e Educação, v. 19, n. 2, p. 295-307, 2017. DOI:

https://doi.org/10.30715/rbpe.v19.n2.2017.10955 . Acessado em: nov. 2020.

VELASCO, I. H. Geração digital: por que, pela $1^{1}$ vez, filhos têm QI inferior ao dos pais. In: Uol. 2020. Disponível em: https://www.uol.com.br/tilt/noticias/bbc/2020/10/30/geracao-

digital-por-que-pela-1-vez-filhos-tem-qi-inferior-ao-dos-pais.htm. Acessado em: nov. 2020.

XAVIER, M. A. G. Informática como instrumento de interdisciplinaridade. RECITE-

Revista Carioca de Ciência Tecnologia e Educação, Rio de Janeiro, v.5, n.2.

DOI: https://doi.org/10.17648/2596-058X-recite-v5n2-3. Acessado em: nov. 2020. 